\title{
Comparison of the Knowledge and Perception of Pharmacovigilance Among Pharmacy, Dental and Medical Students in Aden-Yemen
}

\author{
Mohammed Alshakka ${ }^{1}$, Owsan A Bahattab ${ }^{2}$, Heyam Ali ${ }^{3}$, Gamil Othman $^{4}$, Mukhtar Ansari ${ }^{5}$, Pathiyil \\ Ravi Shankar6, Mohamed Izham Mohamed Ibrahim ${ }^{7}$ \\ ${ }^{1}$ Section of Clinical Pharmacy, Faculty of Pharmacy, Aden University, Aden, YEMEN \\ ${ }^{2}$ Department of Community Medicine and Public Health, Faculty of Medicine and Health Sciences, Aden University, \\ YEMEN \\ ${ }^{3}$ Department of Pharmaceutics, Dubai Pharmacy College, Dubai, UAE \\ ${ }^{4}$ Department of Clinical Pharmacy, College of Pharmacy, University of Science and Technology, Sana'a, YEMEN \\ ${ }^{5}$ Department of Clinical Pharmacy, College of Pharmacy, University of Hail, KSA \\ ${ }^{6}$ Department of Pharmacology, American International Medical University, St. Lucia, CARIBBEAN \\ ${ }^{7}$ Clinical Pharmacy and Pharmacy Practice Section, College of Pharmacy, Qatar University, QATAR
}

Received: 28 July 2017; Accepted: 19 September 2017

*Correspondence to:

Dr. Mohammed Alshakka, PhD, Section of Clinical Pharmacy, Faculty of Pharmacy, Aden University, Aden, YEMEN Email:alshakka400@gmail.com

Copyright: (C) the author(s),publisher and licensee Indian Academy of Pharmacists. This is an openaccess article distributed under the terms of the Creative Commons Attribution Non-Commercial License, which permits unrestricted non-commercial use, distribution, and reproduction in any medium, provided the original work is properly cited.
Abstract

Background: Adverse drug reactions (ADRs) represent a serious health problem. Despite all the benefits of modern medicines, evidence continues to mount that ADRs to them are common, yet often preventable cause of illness, disability and even death. ADRs are responsible for a significant number of hospital admissions. Healthcare professionals have an important role to play in reducing ADRs. Purpose: The goal of this study was to compare the knowledge and attitudes of pharmacy, dental and medical students regard-ing adverse drug reactions (ADRs), as well as their perceptions of barriers to ADR reporting, in Aden University, Yemen. Methods A cross-sectional study was conducted among final-year students. A total of 130 pharmacy students, 101 medical and 69 dental students completed the self-administered questionnaire. The study was conducted from July 1 to October 31, 2016. The responses of pharmacy students were compared to those of dental and medical students. Results: The mean ages of the pharmacy, medical and dental students were $25.13 \pm 1.90$ years. A non-significant gender difference $(P<0.766)$ was found in the mean knowledge score of the participants, with female participants ( $n=137$ ) showing more knowledge of ADR reporting (4.66 \pm 1.888 ) than their male counterparts $(n=163,4.53 \pm$ 1.857). Another important finding of this study was a significant difference $(P<0.001)$ between pharmacy, medical and dental students withknowledge about ADR reporting, with pharmacy students showing a greater degree of knowledge $(5.23 \pm 1.75)$ about ADR reporting than medical students $(3.78 \pm 1.61)$ with the dental students knowledge being intermediate $(4.43 \pm 2.02)$. Conclusion: The results indicate that pharmacy, dentistry and medical students demonstrated lack of understanding knowledge about ADRs. Final-year pharmacy students exhibited more knowledge about ADRs and showed more positive attitudes regarding their capacity to handle and report ADRs than a fiᄀnal-year medical and dental students.

Key words: Aden; dental; Pharmacy; Medical; Students; Pharmacovigilance; Comparison; Yemen. 


\section{INTRODUCTION}

Adverse drug reactions (ADRs) pose a major health problem. ${ }^{[1]}$ Despite the various benefits of modern medicines, evidence that ADRs are common and often cause illnesses, disabilities and even death is growing. ADRs are said to be responsible for a significant percentage of hospital admissions, ranging from $0.3 \%$ to $11 \%{ }^{[2]}$ Over 770,000 people are estimated to suffer from injury or die every year from ADRs. ${ }^{[3]}$ An analysis conducted in the United States (US) indicated that ADRs were between the $4^{\text {th }}$ and $6^{\text {th }}$ most common cause of death in 1997. ${ }^{[4]}$ A 2004 study of hospital admissions in the United Kingdom (UK) revealed that 6.5 per cent of patients in hospitals had some experiences with an ADR. Another study in the UK agrees with other studies and found that ADRs were responsible for 4 per cent of hospital admissions and resulted in a projected annual cost of $f_{4} 466$ million to the National Health Service (NHS). ${ }^{[5]}$ Later another statistical finding of the study demonstrated that over 2 per cent of patients hospitalized with ADRs died. The World Health Organization (WHO) defines an ADR as 'any response to a drug that is noxious and unintended, and that occurs in doses used in humans for prophylaxis, diagnosis, or therapy, excluding failure to accomplish the intended purpose'. ${ }^{[6]}$

Developing countries had registered a higher trend of ADRs. ${ }^{[7]}$ A study from Iran in 1999, showed that approximately $16.8 \%$ of the patients had at least one ADR and $2.9 \%$ of the ADRs were identified as lethal. ${ }^{[8]}$ In another study conducted in South India, an overall incidence of $9.8 \%$ was reported. ${ }^{[9]}$ A retrospective study done in Riyadh, Saudi Arabia reported 54\% of the ADRs to be preventable. ${ }^{[10]}$ To cite another example, in Nepal, the prevalence of ADR was $0.86 \%$ and the male to female ratio was 0.85 and $10.81 \%$, of ADRs were serious. ${ }^{[1]}$ Therefore, monitoring of ADRs is vital in order to reduce their toxicity level and prevent patients from morbidity and mortality. Knowledge of possible ADRs is required before clinical treatment, and people should obtain knowledge about them so that they will remain safe, and they can evaluate the harm, benefits and risk of available drugs. ${ }^{[12]}$

Pharmacovigilance (PV) is defined by the WHO as the science and activities that relate to the detection, assessment, understanding and prevention of adverse effects of drugs or any other possible drug-related problems..$^{[14]}$ Thalidomide was named the greatest tragedy in 1961 and led to the establishment of the current drug regulatory mechanisms. Pharmacovigilance is defined as an arm of patient care that aims at taking advantage of the drugs and medicines to treat or prevent diseases without any unwanted effects. The history of international pharmacovigilance dates back to four decades, when the twentieth WHO assembly passed a resolution to initiate an international system to oversee ADRs. Recently the scope of pharmacovigilance has been widened to include: herbals, traditional and complementary medicines, blood products, biologicals, medical devices and vaccines.

Yemen is an Arab country located in the Southern Arabian Peninsula, and its neighboring countries are the Kingdom of Saudi Arabia, and Oman. With a population of around 20 million, more than $70 \%$ of Yemenis reside in rural areas. The illiteracy rate among its people is about $55.7 \%$. Yemen is a low-income country. The total expenditure on health was not retrievable at the time of writing, but the governmental contribution only represents $2 \%$ of the GDP. In general, the health services are predominantly located in major cities; although primary health centres/units and polyclinics are present nationwide, including some rural areas. ${ }^{[13]}$ The evolution of the local pharmaceutical industry is gradual, and it only represents a small percentage of the total market share. Medicines are imported through private sector agents and they cater to the majority of the country's needs.

There are some important health challenges in Yemen, including the high incidence of both communicable and non-communicable diseases. Yemen also shows higher prevalence of lifestyle risk factors and it also does not have necessary sanitation (especially water, sanitation). ${ }^{[13]}$ At the end of 2011, the SBDMA (Subprime Board for Drugs and Medical Appliances) established a Pharmacovigilance Center, but it has yet to come up with a systematic plan to monitor adverse drug reactions and drug-related issues in Yemen. Spontaneous reporting of ADRs is the foundation of pharmacovigilance and it is a very comprehensive system for maintaining patients' safety. According to the WHO standards, countries with the best reporting rates must generate at most 200 reports per 1,000,000 inhabitants annually. However, the reporting of serious ADRs rarely exceeds $10 \%$. For instance, Yemen with 25 million people is expected to receive 4100 reports annually. Unfortunately, this is not so, people do not have enough information about how, whom and where to report ADR cases, and there is insufficient knowledge about ADR and the role of pharmacovigilance in the improvement of 
health services among the majority of the healthcare professionals. All these are hazardous to patient safety, simultaneously putting people at the risk of fatality due to ADRs every single year. ${ }^{[14,15]}$

Various studies were done to assess students' knowledge of pharmacovigilance and ADRs reporting, and their attitude towards them showed that there is a deficiency of knowledge concerning pharmacovigilance and ADR reporting. ${ }^{[16-21]}$ Therefore the study objective is to assess and compare the knowledge, attitude and practice of pharmacovigilance and adverse drug reporting among final year Pharmacy, Dental and Medicine students in Aden University.

\section{METHODOLOGY}

Study design, duration and study population

This is a descriptive, cross-sectional study conducted among Pharmacy, Dental and Medical final-year students of Aden University, for 2 months, from July 2016 to October 2016.

Study population

The study population included the final-year students of three disciplines (Pharmacy, Dentistry and Medicine). There were 130 pharmacy students, 101 medical students and 69 dental students amounting to 300 students. Each participant was approached individually with regard to their participation in this study.

\section{Measures}

A self-administered questionnaire was used to gather the data from the participants. The questionnaire was administered to the students, and researchers assumed the responsibility of explaining the questionnaire to the students. The questionnaire was also tested for content validity and reliability. A pilot study was also conducted on a small number of Pharmacy, Dental and Medical students $(n=10)$, but their responses were not used in the final analyses.

The final version of the questionnaire was broken down into five sections. The first section included some demographic information. The second section establishes questions that evaluate the knowledge of students concerning ADRs and ADR reporting using 10 multiple-choice questions. One point was allocated for each correct answer and zero points for each incorrect answer. The maximum possible score was 10 and the minimum one was 0 . A score $<7$ was considered to suggest that the knowledge is at a poor level, and a score $\geq 7$ was considered to indicate that the knowledge is at a good level. The third section deals with students' attitude towards ADRs and ADR reporting. This section included 10 questions posed in the final analysis. Responses were measured on a four-point Likert scale, with the score of 1 means strong agreement, 2 agreement, 3 disagreement, and 4 implying strong disagreement. The median perception score of each student was used to ascertain the overall students' perception. A score $\leq 2$ was considered to show an overall positive attitude, while a score $>2$ were considered to show an overall negative attitude. In addition, students' attitudes toward each question using the same scoring method were studied at different times. The fourth and fifth sections of the questionnaire scrutinized students' perceptions of the reasons why ADRs can go unreported and their perceptions for the reporting of ADRs cases in the future, respectively. Students were asked to select the most probable reasons for failing to report ADRs, and multiple selections were presented. A questionnaire was distributed to the participants in personal meetings. Students were explained about the objectives of this study and were informed that completing and returning the questionnaire indicates that they had agreed to take part in this study.

Data were keyed in and studied using SPSS software (version 20.0). Categorical variables were elaborated with the help of the frequency distribution and percentage, while quantitative (ordinal) variables were described through the medians and interquartile ranges (IQR). The percentages were calculated using the total number of responders for every question. Data comparison was done using the Chi-square test for categorical data, and Mann- Whitney U or Kruskal Wallis Test for ordinal data was found to be appropriate. $P$ value $<0.05$ was considered to be statistically significant.

\section{Ethical Consideration}

The study protocol was endorsed by the Ethics Research Committee of the Faculty of Medicine and Health Sciences, Aden University. All the participants had given their verbal consent, meaning that they agreed to participate in the study after the objectives, the importance and benefits of the research are explained and they were informed that the participation is voluntary. The investigators guaranteed that the collected data will be treated with utmost confidentiality, and they will only be used for research works.

\section{RESULT}


A total of 320 questionnaires was distributed; however, only 300 students completed them, yielding a response rate of $93.75 \%$. The mean age and standard deviation of the participants was $25.13 \pm 1.89$ years.

Table 1 shows the demographic characteristics of the respondents and their experience with ADRs.

Table 2 shows the knowledge of pharmacy, dentistry and medical students about ADRs and ADR reporting. The results obtained show that pharmacy students had greater knowledge than medical and dental students for all aspects of ADRs and ADR reporting. However, the discrepancy between pharmacy, medical and dental students differed according to the question. When asked if ADRs can be fatal if not identified and managed in a timely manner, $69.2 \%$ of pharmacy students answered correctly, compared to $58.0 \%$ dental and $43.6 \%$ of medical students. In contrast, the knowledge level of pharmacy, dental and medical students were similar with regard to their awareness of the regulatory body in Yemen regulating ADR reporting (20\%,
$27.5 \%$ and $26.7 \%$, respectively). All groups demonstrated a non-significant difference and poor ability to identify the precise definition of ADRs (5\%,11.6\% and 7.9 respectively). Although participants showed a non-adequate overall knowledge of ADRs, the pharmacy students could identify type A ADRs better than dental and medical students $(74.6 \%, 55.1 \%$ and 42.6 respectively), with a $\mathrm{p}$ value $<$ 0.001 .

The results showed that $266(88.7 \%)$ of all students had an overall positive attitude towards ADRs reporting. Out of the 266 students with positive attitude, 122 $(45.9 \%)$ were pharmacy students (Table 3 ).

Table 4 summarizes the responses of pharmacy, dental and medical students towards attitude statements.

Attitude was assessed numerically by giving a score of 1 to mean strong agreement, a score of 2 to mean agreement, a score of 3 to mean disagreement, and a score of 4 to mean strong disagreement. Scores $<2$ were taken to show positive

\begin{tabular}{llllll}
\multicolumn{6}{l}{ Table 1: The characteristics of the participants $(\mathbf{n = 3 0 0})$} \\
\hline Characteristics & Variables & $\mathbf{N}(\%)$ & Median knowledge scores & IQR & p- value \\
\hline Gender & Male & $163(54.3)$ & 4 & $3-6$ & 0.659 \\
& Female & $137(45.7)$ & 4 & $3-6$ & \\
Experience with ADRs & Yes & $172(57.3)$ & 4 & $3-5$ & $<0.001^{*}$ \\
& No & $128(42.7)$ & 5.5 & $4-7$ & \\
Course & Pharmacy & $130(43.3)$ & 6 & $4-7$ & $<0.001^{\text {** }}$ \\
& Dentistry & $69(23.0)$ & 4 & $3-6$ & \\
& Medicine & $101(33.7)$ & 4 & $3-5$ &
\end{tabular}

Table 2: Students' knowledge regarding ADRs and ADR reporting $(n=300)$

\begin{tabular}{|c|c|c|c|c|}
\hline \multirow{2}{*}{ Knowledge question } & \multicolumn{3}{|c|}{ Correct answer $\mathrm{n}(\%)$} & \multirow{2}{*}{$p$-value* } \\
\hline & Pharmacy & Dentistry & Medical & \\
\hline Definition of ADRs & $11(8.5)$ & $8(11.6)$ & $8(7.9)$ & 0.685 \\
\hline What is PV? & $66(50.8)$ & $39(56.5)$ & $54(53.5)$ & 0.736 \\
\hline Type A ADRs & $97(74.6)$ & $38(55.1)$ & $43(42.6)$ & $<0.001$ \\
\hline Type B ADRs & $86(66.2)$ & $37(53.6)$ & $38(37.6)$ & $<0.001$ \\
\hline $\begin{array}{l}\text { ADRs should be reported only when they are found to be serious and } \\
\text { unanticipated }\end{array}$ & $88(67.7)$ & $31(44.9)$ & $47(46.5)$ & 0.001 \\
\hline Herbal product safety & $96(73.8)$ & $33(47.8)$ & $48(47.5)$ & 0.001 \\
\hline Reporting ADRs associated with herbal drugs and blood product & $97(74.6)$ & $33(47.8)$ & $50(49.5)$ & $<0.001$ \\
\hline ADRs can be FATAL if they are not recognized and treated at the right time & $90(69.2)$ & $40(58.0)$ & $44(43.6)$ & $<0.001$ \\
\hline Knowledge of the national PV center & $23(17.7)$ & $28(40.6)$ & $32(31.7)$ & 0.001 \\
\hline SBDM is the main authority to whom to report ADRs & $26(20.0)$ & $19(27.5)$ & $27(26.7)$ & 0.363 \\
\hline
\end{tabular}

${ }^{\star}$ Derived from the chi-square test. 


\begin{tabular}{|c|c|c|c|}
\hline \multirow{2}{*}{$\begin{array}{l}\text { Category of } \\
\text { students }\end{array}$} & \multicolumn{2}{|c|}{ Attitude about reporting ADRs } & \multirow[t]{2}{*}{$p$ - value* } \\
\hline & Positive & Negative & \\
\hline Pharmacy & $122(45.9 \%)$ & $8(23.5 \%)$ & .010 \\
\hline Dentistry & $62(23.3 \%)$ & $7(20.6 \%)$ & \\
\hline Medicine & $82(30.8 \%)$ & $19(55.9 \%)$ & \\
\hline \multicolumn{4}{|c|}{$\begin{array}{l}\text { Attitude was assessed numerically by giving a score of } 1 \text { to imply strong agreement, } \\
\text { a score of } 2 \text { indicating agreement, a score of } 3 \text { indicating disagreement, and a score } \\
\text { of } 4 \text { indicating strong disagreement. Scores }<2 \text { were taken to suggest on positive } \\
\text { attitudes, while scores } \geq 2 \text { would mean negative attitudes. }\end{array}$} \\
\hline
\end{tabular}

attitudes, while scores $\geq 2$ showing negative attitudes.

These are taken from the chi-square test.

Most students believed that the lack of information about pharmacovigilance was the main reason why people are not reporting ADRs; more medical students $(84.2 \%)$ agreed to this statement compared to pharmacy students $(79.9 \%)$ and dental students $(72.5 \%)$. This difference was not statistically significant $(\mathrm{P}<0.168)$. Also, the groups had reported the authorities were not encouraging enough about reporting ADRs. In addition, there was a statistically significant difference when students were asked about the fear of facing legal problems $(74.6 \%, 65.2 \%$ and $47.5 \%$, respectively among pharmacy, dental and medical students).

In case of future questions, the pharmacy students show a high percent of answers when they were asked about the role of information technology in facilitating ADRs reporting, there was a statistically significant difference among pharmacy students $(81.5 \%)$, dental students (72.5) and medical students (62.4\%).

On the other hand, the medical students had the highest percentage $(72.3 \%)$ when asked if they offered support to a direct ADR reporting by patients rather than the healthcare professionals; while $47.8 \%$ of dental students and $43.8 \%$ of pharmacy students were in unison about this. This difference is statistically significant. The response of pharmacy, dental and medical students toward the future questions is summarized in Table 6.

Table 4: Students' attitude towards ADRs and ADRs reporting

\begin{tabular}{|c|c|c|c|c|}
\hline \multirow{2}{*}{ Perception question } & \multicolumn{3}{|c|}{ Positive attitude $n(\%)$ Students } & \multirow{2}{*}{$p$-value } \\
\hline & Pharmacy & Dentistry & Medical & \\
\hline ADR topics are well covered in my curriculum & $107(82.3)$ & $55(79.7)$ & $84(83.2)$ & 0.841 \\
\hline As a member of the profession, I think that it is my responsibility to report ADR & $116(89.2)$ & $57(82.6)$ & $77(76.2)$ & 0.031 \\
\hline Have you seen the ADR reporting form? & $62(47.7)$ & $38(55.1)$ & $58(57.4)$ & 0.306 \\
\hline Were you trained to complete the ADRs reporting form? & $51(39.2)$ & $25(36.2)$ & $49(48.5)$ & 0.212 \\
\hline I believe that I will have sufficient knowledge of ADR reporting in my future practice & $115(88.5)$ & $52(75.4)$ & $74(73.3)$ & 0.008 \\
\hline I believe that my profession is vital when it comes to reporting ADRs? & $79(60.8)$ & $49(71.0)$ & $7372.3 \%$ & 0.131 \\
\hline I believe ADR reporting should be made mandatory for all healthcare professionals & $109(83.8)$ & $49(71)$ & $7069.3 \%$ & 0.020 \\
\hline $\begin{array}{l}\text { Concerned authorities are not working actively to enhance the ADR reporting } \\
\text { system in Yemen }\end{array}$ & $105(80.8)$ & $58(84.1)$ & $62(61.4)$ & $<0.001$ \\
\hline Do you think reporting ADRs can become a hassle in the working environment? & $84(64.6)$ & $35(50.7)$ & $47(46.5)$ & 0.016 \\
\hline Do you believe that reporting ADRs will bring an improvement in patients' safety? & 115 (88.5) & $59(85.5)$ & 76 (75.2) & 0.024 \\
\hline
\end{tabular}

Table 5: Reasons for not reporting ADRs $(n=300)$

\begin{tabular}{|c|c|c|c|c|}
\hline \multirow{2}{*}{ Reason question } & \multicolumn{3}{|c|}{ Students' reasons for not reporting $\mathrm{n}(\%)$} & \multirow{2}{*}{$p$ - value* } \\
\hline & Pharmacy & Dentistry & Medical & \\
\hline Information not provided by patients & $100(76.9)$ & $50(72.5)$ & $85(84.2)$ & 0.168 \\
\hline I do not have enough time & $52(40.0)$ & $34(49.3)$ & $53(52.5)$ & 0.144 \\
\hline I have no idea where and how to report & $87(66.9)$ & $43(62.3)$ & $63(62.4)$ & 0.715 \\
\hline I do not consider it important & $33(25.4)$ & $28(40.6)$ & $38(37.6)$ & 0.046 \\
\hline It is not promoted widely by the authorities & $93(71.5)$ & $51(73.9)$ & $69(68.3)$ & 0.720 \\
\hline I fear facing legal problems & $97(74.6)$ & $45(65.2)$ & $48(47.5)$ & $<0.001$ \\
\hline
\end{tabular}


Table 6: Future of ADRs reporting $(n=300)$

\begin{tabular}{|c|c|c|c|c|}
\hline \multirow{2}{*}{ Future of ADRs reporting } & \multicolumn{3}{|c|}{ Responses n (\%) students } & \multirow{2}{*}{ p- value } \\
\hline & Pharmacy & Dentistry & Medical & \\
\hline Do you support "Direct ADR Reporting" to be done by the patients? & $57(43.8)$ & $33(47.8)$ & $73(72.3)$ & $<0.001$ \\
\hline $\begin{array}{l}\text { Do you see the role of information technology in helping to advance ADR } \\
\text { reporting in the country? }\end{array}$ & $106(81.5)$ & $50(72.5)$ & $63(62.4)$ & 0.005 \\
\hline $\begin{array}{l}\text { Do you think the relevant authority should maintain an online website like other } \\
\text { countries who have records of the ADRs all across the nation? }\end{array}$ & $94(72.3)$ & $47(68.1)$ & $64(63.4)$ & 0.350 \\
\hline $\begin{array}{l}\text { Are you of the opinion that this online program/website should be accessible } \\
\text { to everyone freely? And ADR reporting procedure be made compulsory to } \\
\text { pharmacists at their workplace? }\end{array}$ & $92(70.8)$ & $47(68.1)$ & $65(64.4)$ & 0.584 \\
\hline $\begin{array}{l}\text { Should legal protection be provided to the pharmacists if they have dispensed } \\
\text { the medication that causes ADR? }\end{array}$ & $101(77.7)$ & $40(58.0)$ & $67(66.3)$ & 0.046 \\
\hline
\end{tabular}

\section{DISCUSSION}

We believe that this research is the first study of the knowledge and perception of pharmacovigilance among final-year pharmacy, dentistry and medical students of Aden University in Aden and the second to be carried out in Yemen. The study has the goal of comparing the knowledge and attitude of pharmacy, medicine and dentistry students toward PV. This study observed that there is an inadequate level of knowledge about ADR and pharmacovigilance. Similar studies conducted in other developing nations gave the same results. ${ }^{[16-20]}$ These findings can perhaps be attributed to the shortage of courses on ADR and PV in their educational content. ${ }^{[21-22]}$

More than half of the pharmacy students (67.7\%) stated that ADR should be reported only when they feel that the cases are severe compared to dentistry $(44.9 \%)$ and medical students stating the same (46.5\%). Additionally, $73.8 \%$ of pharmacy students stated that herbal products have no $\mathrm{ADR}$ and are safe. This shows their unawareness of the dangers that ADRs could pose. Also, more than half of the pharmacy students $(67 \%)$ stated that ADR could be fatal if not identified and managed compared to dentistry students $(68 \%)$ and medical students (43.6\%). Our study observes that there is no nearest pharmacovigilance center located in the study area in effect it is not very much promoted by the relevant authorities.Students also have poor knowledge about the national pharmacoviglance program; therefore ADR topics should be included in the curricula of pharmacy, dentistry, and medical students so that their knowledge can be enhanced ${ }^{[23]}$ The attitude of the pharmacy towards these issues was more positive compared to the medical and dentistry students. This result is harmonious with the result of previous studies whereby pharmacists develop a positive attitude towards how they can handle and report $\mathrm{ADR}^{[23]}$

It was observed that students had challenge completing the ADR reporting form, this could be attributed to their lack of training in ADR reporting. ${ }^{[20,21]}$ To help students with positive attitudes towards reporting ADR in their future practice, there is a need to include training in ADR and PV in their curricula ${ }^{[23]}$ to improve the clinical outcomes and promote the rational use of drugs. ${ }^{[24-26]}$ More than half of the study population strongly agreed that ADR reporting should be made mandatory for professionals, indicating that students have positive perception towards PV and ADR reporting. The present study also found out that information not being provided by patients and weak promotional activities from the authorities was the major reasons that led to the failure in reporting ADR. $81.5 \%$ of pharmacy students compared to $72.5 \%$ of dentistry and $62.4 \%$ of medical students envisaged the role of information technology in facilitating ADR reporting in the country in the future and they think that the relevant authority in Yemen should maintain an online program or website like other countries that can be accessed by everyone in the future.

Limitation: The limitations of this study are the students who participated were final year pharmacy, dentistry and medical students. Additionally, this study was only carried out in Aden University; so, perhaps, future studies can consider the knowledge and perception in other localities.

\section{CONCLUSIONS AND RECOMMENDATIONS}

The results of the present study highlight the fact that a large proportion of the students in Aden University do 
not have adequate knowledge about pharmacovigilance practices. Final-year pharmacy students did show greater knowledge about ADRs and developed more positive attitudes to handle and report ADRs than the senior medical and dental students.

ADR reporting and pharmacovigilance practice need to be well implemented in order to improve ADRsreporting. ADR-related monitoring and pharmacovigilance activities are still inadequate in a lot of countries where drug safety problems are widespread. Yemen must institute a 'Pharmacovigilance Program' and build Pharmacovigilance Centers in collaboration with regulatory bodies such as SBDMA and medical and pharmacy schools. An awareness program for local pharmaceutical companies, healthcare professionals and patients that inform them about ADR detection and reporting has to be planned and implemented.

Educational programs and the training of future students should be the first task that must be taken up by the stakeholders such as governmental agencies, schools of pharmacy and medicine as well as the pharmaceutical industry so as to improve and encourage healthcare professionals to be part of the ADR reporting process. SBDMA in Yemen should also guide the public or the patients in particular throughout the process of reporting by making reporting forms user-friendly and available either online or on paper or both, consistently. Proper feedback needs to be consistently prepared and delivered to the reporters so that ADRs reporting has a chance for improvement.

\section{ACKNOWLEDGEMENT}

Our thank go to 20 fifth year students of Faculty of Pharmacy Aden for the data collection

\section{CONFLICT OF INTEREST}

None

\section{ABBREVIATION USED}

ADRs: adverse drug reactions, SBDMA: Subprime Board for Drugs and Medical Appliances etc.

\section{REFERENCES}

1. International Drug Monitoring: The Role of National Centres. Geneva: World Health Organization, 1972.

2. The importance of pharmacovigilance. Geneva; World Health Organization:
2002.

3. Classen DC, Pestotnik SL, Evans RS. Adverse drug events in hospitalized patients. JAMA 1997;277(4):301-6.

4. Lazarou J, Pomeranz BH, Corey PN. Incidence of adverse drug reactions in hospitalized patients: a meta-analysis of prospective studies. JAMA 1998;279(15):1200-5.

5. Pirmohamed M, James S, Meakin S. Adverse drug reactions as cause of admission to hospital: prospective analysis of 18,820 patients. BMJ.2004;329(7456):15-9.

6. Lee A, Thomas SHL. Adverse drug reactions In: Walker R and Edward C. Clinical pharmacy and Therapeutics. $3^{\text {rd }}$ edition Churchill Livingstone 2003:33-46.

7. Pourseyed S, Fattahi F, Pourpak Z, Gholami K, Shariatpanahi SS, Moin Aet al., Adverse drug reactions in patients in an Iranian department of internal medicine. Pharmacoepidemiol Drug Saf. 2009;18(2):104-10.

8. Gholami K, Shalviri G. Factors associated with preventability, predictability, and severity of adverse drug reactions. Ann Pharmacother.1999;33(2):236-40.

9. Ahmad A, Patel I, Balkrishnan R, Mohanta GP, Manna PK. An evaluation of knowledge, attitude and practice of Indian pharmacists towards adverse drug reaction reporting: A pilot study. Perspect Clin Res. 2013;4(4):204-210.

10. Al-Malaq HM, Al-Aqeel SA, Al-Sultan MS. Adverse drug reactions related hospitalization identified by discharge ICD-9 codes in a university hospital in Riyadh. Saudi Med J.2008(8):1145-50.

11. Jha N, Bajracharya $\mathrm{O}$, Namgyal T. Prevalence of adverse drug reactions with commonly prescribed drugs in different hospitals of Kathmandu valley. Kathmandu Univ Med J. 2007;(4):504-10.

12. Safety of medicines: A guide to detecting and reporting adverse drug reactions. World Health Organization, Geneva, 2002.

13. Yemen Pharmaceutical Country Profile; Published by the Ministry of Public Health and the Population of the Republic of Yemen, in collaboration with the WHO, 2011.

14. Alshakka M, Ibrahim MI, Hassali MA, Palaian S, Aljadhey H. Hazards of Pharmaceuticals in Water as New Area in Eco-Pharmacovigilance Research. J Pharm Pract Community Med. 2016;2(1):3-8.

15. Alshakka M, Bassalim $H$, Alsakkaf $K$, Mokhtar M, Alshagga M, AL-Dubai $\mathrm{S}$, Jha N, Abdoraboo A and Shanker PR. Knowledge and perception towards pharmacovigilance among Healthcare professionals in Tertiary care Teaching Hospital in Aden, Yemen. J Pharm Pract Community Med. 2016;2(1):21-8.

16. Sivadasan S. Sellappan M. A Study on the Awareness and Attitude Towards Pharmacovigilance and Adverse Drug Reaction Reporting Among Nursing Students in a Private University, Malaysia. Int J Current Pharm Res. 2015;7(2):84-9.

17. Shalini S, Mohan S. Knowledge and Attitued towards Pharamacovigiliance and Adverse drug Reaction reporting among dental students in a private University, Malaysia. J Young Pharmacists. 2015;7:119.

18. Elkalmi RM, Hassali MA, Ibrahim MIM, Widodo RT, Efan QM, Hadi MA. Pharmacy students' knowledge and perceptions about pharmacovigilance in Malaysian public universities. Am J Pharm Edu. 2011;75(5):96.

19. Raza A, Jamal H. Assessment of Knowledge, Attitudes and Practice among the Medical and Pharmacy Students towards Pharmacovigilance and Adverse Drug Reactions in Abbottabad, Pakistan. J Pharmacovig. 2015;3:4.

20. Farha RA, Alsous M, Elayeh E, Hattab D. A Cross-Sectional Study on Knowledge and Perceptions of Pharmacovigilance among Pharmacy Students of Selected Tertiary Institutions in Jordan. Trop J Pharm Res.2015;14(10):1899-905.

21. Khan MU, Ahmad A, EjazA, Rizvi SA, Sardar A, Hussain K et al., Comparison of the knowledge, attitudes, and perception of barriers regarding adverse drug reaction reporting between pharmacy and medical students in Pakistan. J Educ Eval Health Prof. 2015;12:28.

22. Othman GQ, Ibrahim MIM, Alshakka M, Ansari M, Qadasi FA, Halboup AM. Knowledge and Perception about Pharmacovigilance among Pharmacy Students of Universities in Sana'a Yemen. J Clin Diag Res. 2017;11(6): FC09-FC13

23. Farha RA, Alsous M, Elayeh E, Hattab D. A Cross Sectional Study on Knowledge and Perceptions of Pharmacovigilance among Pharmacy Students of Selected Tertiary Institutions in Jordan. Trop J Pharm Res. 
Alshakka et al.: Knowledge and Perception about Pharmacovigilance among Health care students

2015;14(10):1899-1905.

24. Ahmad A, Khan MU, Patel I, Maharaj S, Pandey S, Dhingra S. Knowledge, attitude and practice of B.Sc. Pharmacy students about antibiotics in Trinidad and Tobago. J Res Pharm Pract. 2015; 4(1):37.

25. Rafi MS, Naqvi SB, Khan MU, Fayyaz M, Ashraf N, Khan MA et al.,
Evaluation of Potential Drug-Drug Interactions with Antidepressants in Two Tertiary Care Hospitals. JCDR. 2015;9(7):FC05.

26. Sartelli M, Labricciosa FM, Barbadoro P, Pagani L, Ansaloni L, Brink AJ et al., The Global Alliance for Infections in Surgery: defining a model for antimicrobial stewardship-results from an international cross-sectional survey. World J Emerg Surg. 2017;1;12(1):34.

Cite this article as: Alshakka M, Bahattab OA, Ali H, Othman G, Ansari M, Shankar PR, Ibrahim MIM. Comparison of the Knowledge and Perception of Pharmacovigilance Among Pharmacy, Dental and Medical Students in Aden-Yemen. J Pharm Pract Community Med. 2017;3(4):254-61. 